\title{
Functional Requirement and Performance on Analysis of Computer Network Teaching System
}

\author{
Jingxian Wang \\ Department of College Foundation Education, Bohai University, Jinzhou, 121013, China \\ wjx_0610@126.com
}

\begin{abstract}
Keywords: computer network; teaching system; system analysis; requirement analysis; functional
\end{abstract} requirement; performance requirement

\begin{abstract}
The development of modern education needs the network system of online teaching, the needs analysis is the basic work to build an network system of online teaching. Clarify the tasks and the process of needs analysis based on and study functional requirements analysis and analysis of performance requirements. Functional requirements analysis, build the structure of the functional modules of the network system of online teaching, from teaching organizations, online communication, online assessment, teaching resources, online management; performance needs analysis is from the number of online users, software, response speed, the system stability and other aspects of the analysis. This study content to improve teaching effectiveness, and accelerate the EFA process must have a profound impact.
\end{abstract}

\section{Introduction}

Computer network teaching system is the integrated network for "teach" and "learning" environment, the teachers on the system open network courses, learners choose to learn the curriculum and learn. Network teaching is the need of China's educational development, mainly in the following areas: efforts to promote EFA balance, coordination and sustainable development and achieve the EFA broader, better, update the target to provide personnel for modernization and intellectual support, and make due contribution to the progress and development of human society, it is not enough to rely solely on face-to-face teaching and learning; in different regions, the quality of teachers in different schools is quite different structure of teachers that should be further improved. Regional imbalances in the distribution of our teachers, especially in the rural areas remote and poor lack of teachers, lack of reasonable allocation of teacher resources and take full advantage of teacher resources. Through the network of education, can improve the quality of teachers, narrow the gap; the implementation of modern education, the formation of open education network, a system of lifelong learning, fully utilizing and optimizing our educational resources, popularizing and improving the quality and reducing the cost of education for all people to enjoy fully the right to education is the inevitable trend of development of education and the easiest way is to network teaching.

Network teaching has its unique advantages: rich teaching resources, teaching the content of the performance of various forms, teaching time and space broke through the traditional time and space constraints, diversification of interactive, teacher-student relationship breakthrough single limit [1]. Network teaching system can take full advantage of LAN and the Internet in teaching, reflecting the characteristics that teacher-led builds the students to participate fully in, combine with the development of personalized independent learning, and achieves the sharing of teaching resources and educational social and learning life. This research about building teaching system of online teaching basic work is great significance to promote the sustainable development of online teaching.

\section{Task of Requirement Analysis}

Software requirement analysis task, is not sure how to accomplish the work, but to determine the system must be completed, complete, accurate, clear and specific requirements is the target system. The main job is in-depth description of software functionality and performance, determine the 
details of the limitations of the software design and software interfaces with other elements define the effectiveness of the software requirements, study user requirements, express accurately the accepted user requirements, determine the development of software systems elements, and finally the functions and information structures are assigned to the elements of these systems. Therefore, the task of requirement analysis, by means of the logical model of the current system, export the logical model of the target system to solve what target system does, shown in Fig. 1.

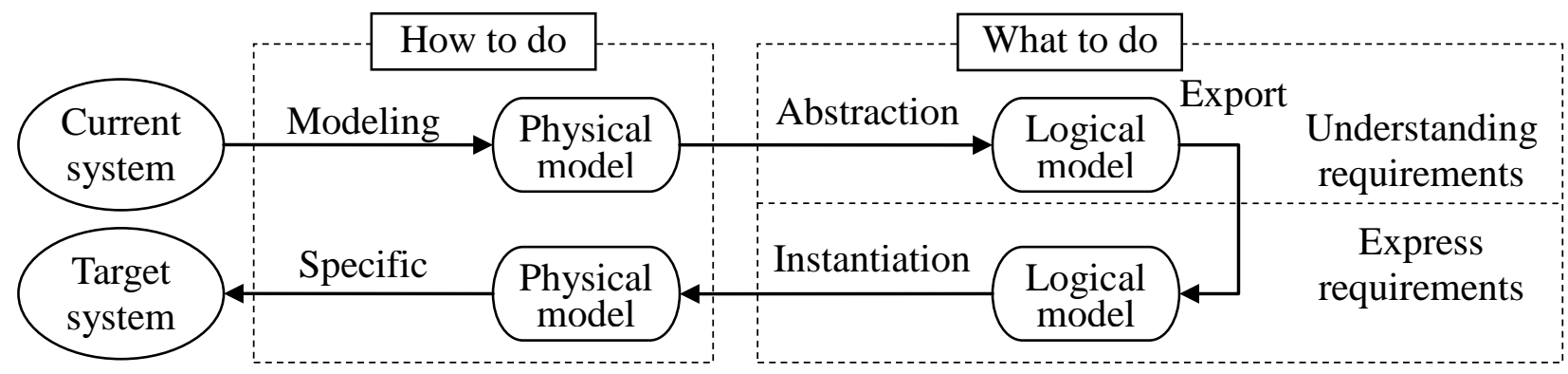

Fig. 1. Refer to the current system to establish the target system model

\section{Functional Requirements Analysis}

Users use functionality provided by the software to understand, use and evaluation systems through the use of software features to complete their business. Functional requirement is the most important elements of the need analysis. Functional analysis based on the software target, form the described software functional model, and qualitatively or quantitatively describes the software functionality requirement. The functionality of the network system of online teaching module structure is shown in Fig. 2.

(1) Teaching organization. Teaching network platform, based on professional training objectives, lesson plans developed by the teaching objectives, determine the course content and organize the network platform, in accordance with good content, teachers can expand the teaching in the classroom. Good online teaching organization should have the following features: Automated Course Scheduling. Characteristics to adapt to online teaching, taking into account curriculum, teachers, students, the various needs to automate curriculum, according to actual needs, being able to manually choreography and changes or semi-automated orchestration; Lesson plans. Lesson plans including professional plans, annual plans, term plans, curriculum. Online student or teacher can check their own lesson plans, in order to prepare class in advance, preview, or other preparatory work. The student can choose appropriate courseware for learning, can also be selected based on their hobbies or time and energy to other courseware; Automatic attendance. Teaching and student lectures are automatically recorded as the attendance of the original data, and automatically generate reports, as one of the basis of the final assessments; Online teaching. Taught through the network, the students choose the basis of the arrangement the day's lecture notes, can directly read the text outline, learn courseware containing the corresponding simulation training, etc., can also do the practice of handouts referenced in the classroom.

(2) Online communication. Students and teachers are provided a system for exchange ,key features include: Classroom questions for. Doubts can ask teachers encountered by students in class, the teacher gives the answer. Teachers ask questions to one or all of the students, the student reply. Questioning message mechanism, questions to answer content without page refreshed would instantly be able to respond, similar QQ functionality; Group discussion. Students are freedom to create discussion group or allocation group determined by teachers and students discuss a custom theme. Student can be divided into several groups according to the inclinations and preferences, the students voluntarily choose to join; Courses communication space. Synchronous or asynchronous communication tools to provide users enhance learning. A course to create more space for different groups and the class is open; System for the public communication area. Provide system-level public communication space; administrators and teachers can organize in a virtual organization, manage outside the classroom; students can participate in the societies exchange. 


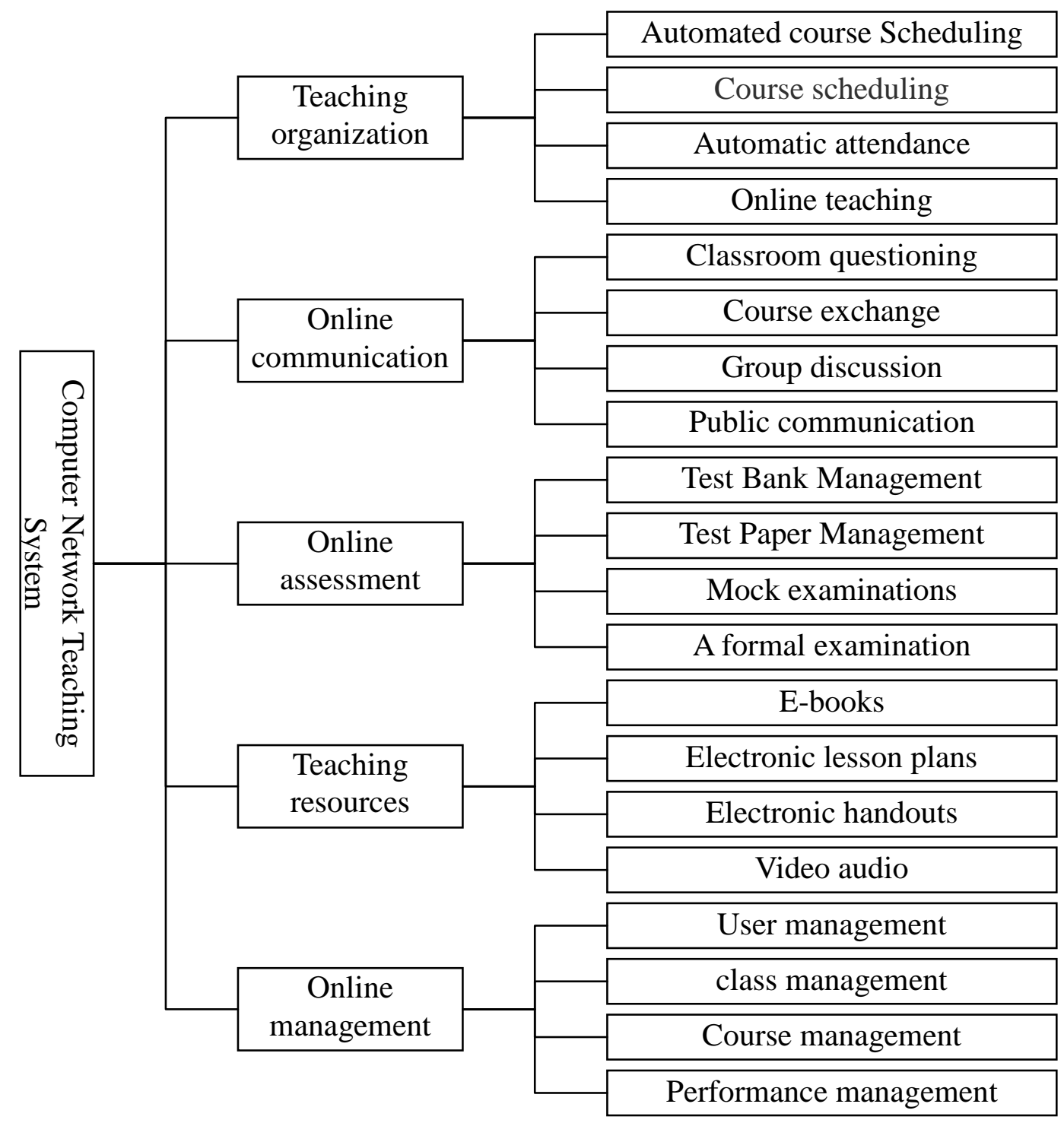

Fig. 2. Module structure of the computer network teaching system

(3) Online assessment. Manage a series of work for assessment. Key features include: Exam. Add, delete or modify all types of item content. Questions can be a real environmental problems, can also be a simulation titles; Test paper. Before the exam administrator set the exam parameters (such as test level, difficulty proportion and number of examination time, score, the proportion of a variety of kinds of questions, the proportion of the knowledge points, etc.), and save these parameters. Generate for different candidates with different exam papers (questions are different in content, but identical to the difficulty of the program and type); mock examinations. Students listen to teachers in or select the appropriate analog papers according to their needs, given the mark and the correct answer after the end of the examination. Later, the students can also see the feedback of teachers for the mock examinations. By mock examinations, teachers can check students' learning, to find the deficiencies and provide assistance to students familiar with the exam before the formal examination environment to reduce unnecessary mistakes; Formal examination. Candidates enter the test number, password, and then papers are generated, candidates must complete the answer sheet in the prescribed time. Teachers score on the subject of the need manually, the automatic scoring of the rest of the subject by the examination system. Teachers can also be based on actual needs to provide students with the correct answer.

(4) Teaching resources. Teaching resources are for the effective conduct of teaching material and the availability of other conditions, usually including teaching materials, case studies, video, pictures, courseware also includes teacher resources, teaching aids, infrastructure and etc., 
Generalized should also be related to the contents of the education policy. Function of network resources is changed from a mere presentation system of teaching resources to online self-study, independent research, teaching interactive system for collaborative discussion [2]. With the development of modern educational technology, teaching resources have been referred to a very important position, concerning with teaching resources, and strengthening the understanding of the teaching resources and research is an extremely urgent task. Teaching resources can be understood all available in education, teaching material conditions, natural conditions, social conditions and media conditions, teaching materials and information sources [3]. Environment of teaching resources, learning needs of students under the guidance of teachers, students use resources. Teachers and teaching administrators, according to the needs of teaching upload the relevant teaching materials. These data can be handouts, courseware, and teaching materials. Students check the information they need at any time and download. So that teachers can not only rely on the specified handouts taught to students, but also allows students to learn in the Download Center, which is the highlight of teaching personalized.

(5) Online management. Manage a variety of information. Key features include: User Management. Add, modify, and delete user information and assign user rights. The role is a collection of a set of permissions, the system establish a number of roles, and assign different roles to enable different users with different permissions for different users. Users, include students, teachers, teaching administrators, courseware administrators, classroom practice administrator, the administrator of mock examinations, examination environmental restoration staff, scoring the examinations staff and system administrators, etc.; Class Management. Add, delete, and set up classes and for the class distribute students, teachers and teaching programs; Course management. Courses that students in online learn are objects, which is instructional design and the main way of online teaching, so, course management is very important to facilitate the students, teachers and management [4]; Performance management. Authorized officers review the candidates examination results and can modify the results of the candidates, the candidates could understand their test scores, different levels of staff can learn about the candidates' results within the scope of its authority.

\section{Performance Need Analysis}

Software technical performance indicators, mainly include the accuracy, the time characteristic of requirement and flexibility [5]. Accuracy, the accuracy of the software inputting and outputting data requirements may include the accuracy of the transmission process; Time feature requests. Note the time characteristics of the software, including response time, update processing time, data conversion and transfering time, computation time; flexibility. Instructions on the flexibility of the software requirements, when needs change, the software is ability to adapt to change. Include changes of mode of operation, the operating environment changes, changes in the interface with other software, the accuracy and validity of changes, planned changes or improvements. Specifically designed to provide these flexibilities section should be marked. Computer network teaching system for performance requirements are in the following aspects [6,7]:

(1) The system burden the number of online users at the same time. Network teaching system is for a school, also for society as a whole. Large number of users use the time to focus, which requires the system to support a considerable number of users simultaneously access to it and frequently playback, browse, download and other operations. For smaller schools, you should allow 1000 users to simultaneously access to it; larger comprehensive university, should allow 10,000 simultaneous users to access; network teaching for society as a whole, with the increase in the number of users set up multiple servers to meet the growing needs of the user.

(2) The software response time. In order to ensure quick and efficient online learning, it requires a higher response speed. We should take full account of the rational allocation of a reasonable indicator of server hardware, database systems and software coding stability. In the system development process, the system current and future amount of data storage and network requirements should be fully considered. General browser playback operation should be controlled 
within 5 seconds, download or combination of conditions more inquiries should be controlled within 20 seconds.

(3) Stability of the system. Network teaching system is used in teaching, the entire teaching process with a sustained, long-term and correctness of the characteristics of long-term activities, which requires that the system has good stability, in order to be able to guarantee the continuity of the user's learning activities, and access to the correctness of the knowledge and resources; Also ensure that teachers publish teaching resources and student assessment accuracy, and the administrator manage the system accuracy and efficiency .

(4) Other properties include ease of use, ease of maintenance, openness and scalability. Ease of use, users do not need specialize training, the system provides a complete user manual and online help for the user during operation; ease of maintenance, software BUG is inevitable, as far as possible in the system testing and commissioning stage problems are detected, the system is running through a simple configuration management that can be completed; openness and scalability, the system in development process takes full account of the openness and scalability of the system to adapt to changes in the operating environment of software development and software changes in demand.

\section{Conclusion}

With the rapid development of information technology today, the content, structure and method of education must be reformed to adapt to the needs of society evolving. Through the integration of modern information technology and curriculum, teaching model construct on the network environment and network system to enable learners through interaction with the network environment and access to knowledge and ability. Through the implementation of the network modeling, so that learners have access to information, process information, create information, performance information and the ability of the transmission of information to search for knowledge and Innovative. A variety of teaching resources integrated into a unified system for teaching, assemble each module in the system and teaching system can make the most appropriate guidance for each learner, learners want to learn the contents of the teaching system that can be quickly find features of the future development trend of the online teaching system. With the support of Modern Information technology, the development of integrated system of online teaching has a profound impact on accelerate the EFA.

\section{References}

[1] Y. M. Feng, S.G. Yan, "Network teaching organization form and strategy selection," Journal of Shenyang Normal University (Social Science Edition), vol. 35, no. 1, pp. 147-149, 2011.

[2] J. L. Chu, Z.J. Liu, "Function analysis and module designing for general teaching resources of the network platform," Electronic Design Engineering, vol. 19, no. 20, pp. 118-120, 2011.

[3] Baidu Encyclopedia, "Teaching resources," http://baike.baidu.com/view/3039812.htm, 2014-6-10.

[4] Q. Z. Wang, "The design and Realization of network teaching platform," Master's Degree of Heilongjiang University, 2010.

[5] Ren YC, E X, Li CJ, et al., "Software Project Developmental Method and Management," Tsinghua University Press, 2010.

[6] Z. Wang, "Design and Implementation on Network Teaching System of Anhui Commerce Institute," Engineering Master Dissertation of University of Electronic Science and Technology of China, 2009.

[7] Levesun N G, "Software safety: why, what, and how," Computing Surveys, vol. 18, no. 2, pp. 125-163, 1986. 